\title{
Forecasting Thermal Stratification of the Victoria Reservoir using a Hydrodynamic Model
}

\author{
K.D.W. Nandalal, S. Piyasiri and K.G.A.M.C.S. Abeysinghe
}

\begin{abstract}
Strong thermal stratification in a reservoir may result in oxygen depletion along the vertical profile downwards leading to its eutrophication. The paper is an investigation of thermal stratification behaviour of the Victoria reservoir in Sri Lanka, which experienced several water quality linked problems in the past. A one-dimensional reservoir hydrodynamics model is calibrated and validated for the Victoria reservoir. The calibration and validation are strengthened by calculating several goodness-of-fit statistics. The study further shows the possibility to change the strong thermal stratification of the Victoria reservoir by manipulating the releases from it. The model that ensures a reasonable prediction of thermal stratification enables taking precautionary measures to avoid adverse reservoir water quality conditions.
\end{abstract}

Keywords: Reservoir, Thermal stratification, Hydrodynamic modeling

\section{Introduction}

When a flowing river is dammed and becomes an impoundment two major changes, which have a marked effect on water quality, occur. Firstly, creating an impoundment greatly increases the time required for water to travel the distance from the headwaters to the discharge at the dam. Secondly, thermal or density and therefore, chemical stratification may take place. Both increased detention time and thermal stratification frequently cause adverse water quality conditions in reservoirs.

The desire to manage the quality of water stored in reservoirs led to the development of numerical models for the simulation of internal dynamics of them. Lakes or reservoirs that do not show significant thermal stratification during the yearly cycle could be modeled assuming complete mixing is occurring throughout its volume during the whole year (O'Connor \& Mueller 1970; Nandalal 1995). However, for reservoirs in which the foregoing condition does not apply, complex models have to be developed to predict thermal gradients, density stratification and the impact that various operating rules may have on these and other physical, chemical and biological quality characteristics of the impoundment water.

Much of the development in modeling reservoir dynamics has been done by assuming onedimensionality, where vertical motion is inhibited and transverse and longitudinal variations are quickly evened out. Even with this simplification, it is difficult to model the interactions of a number of complex processes occurring in a reservoir. Over the last several decades diverse models of varying complexity and success have been produced (Dake \& Harleman 1969; Huber et al. 1972; Markofsky \& Harleman 1973; Imberger et al. 1978; Imberger \& Patterson 1981; Hostetler \& Bartlein, 1990).

There has also been to a less extent some development of two and three dimensional stratification models. However, the increasing complexity and computational requirements have severely limited their development. Although three dimensional models describe the water quality and ecology of reservoirs better, one dimensional models remain attractive, appropriate and convincing for understanding the physical processes occurring in reservoirs (Orlob 1983; Hamilton \& Schladow 1997; Joehnk \& Umlauf 2001, Abeysinghe et al. 2005).

Dynamic Reservoir Simulation Model (DYRESM) is a one-dimensional numerical model that can simulate thermal behaviour and water quality distribution in a reservoir and predict the distribution of temperature (and therefore, density) in reservoirs in response to

Eng (Prof) K.D.W. Nandalal, C Eng., FIE(SL), BScEng, $M E n g, P h D$, Professor of Civil Engineering, Department of Civil Engineering, University of Peradeniya.

Prof. S. Piyasiri, BSc, PhD, Senior Professor of Zoology, Department of Zoology, University of Sri Jayawardenapura.

K.G.A.M.C.S. Abeysinghe, BSc, MPhil 
meteorological forcing, inflow and outflow. The model provides a means of predicting seasonal and inter-annual variability of lakes and reservoirs as well as sensitivity testing to longterm changes in environmental factors or watershed properties.

Several reservoirs in the Mahaweli Project experienced water quality linked problems in recent times. The model DYRESM was calibrated and validated for the Victoria reservoir to predict water level, temperature, salinity and density in it. Calibration and validation were strengthened by calculating several goodness-of-fit statistics.

The paper first presents a brief description of the Victoria reservoir and its catchment. It is followed by descriptions of DYRESM and the statistical methods used in the study. Analysis carried out including calibration and verification of the model for the Victoria reservoir, a statistical analysis, a study on the impact of releases on reservoir thermal stratification are provided next. Finally the conclusions are given.

\section{Site Description}

Victoria reservoir (Figure 1) is a large deep water body resulted from the "Mahaweli Development Scheme" due to construction of a dam across the river Mahaweli in Sri Lanka in 1983, mainly for hydroelectric power generation. Table 1 presents general and morphometric characteristics and physicochemical data of the Victoria reservoir. The Victoria reservoir receives water from its catchment of approximately $1891 \mathrm{~km}^{2}$. It gets water from Hulu River and Mahaweli River (releases from Kotmale reservoir via Polgolla barrage).

Table 2 presents monthly averages of climatological data collected at a recording station close to Victoria dam over the period from 1992 to 1999.

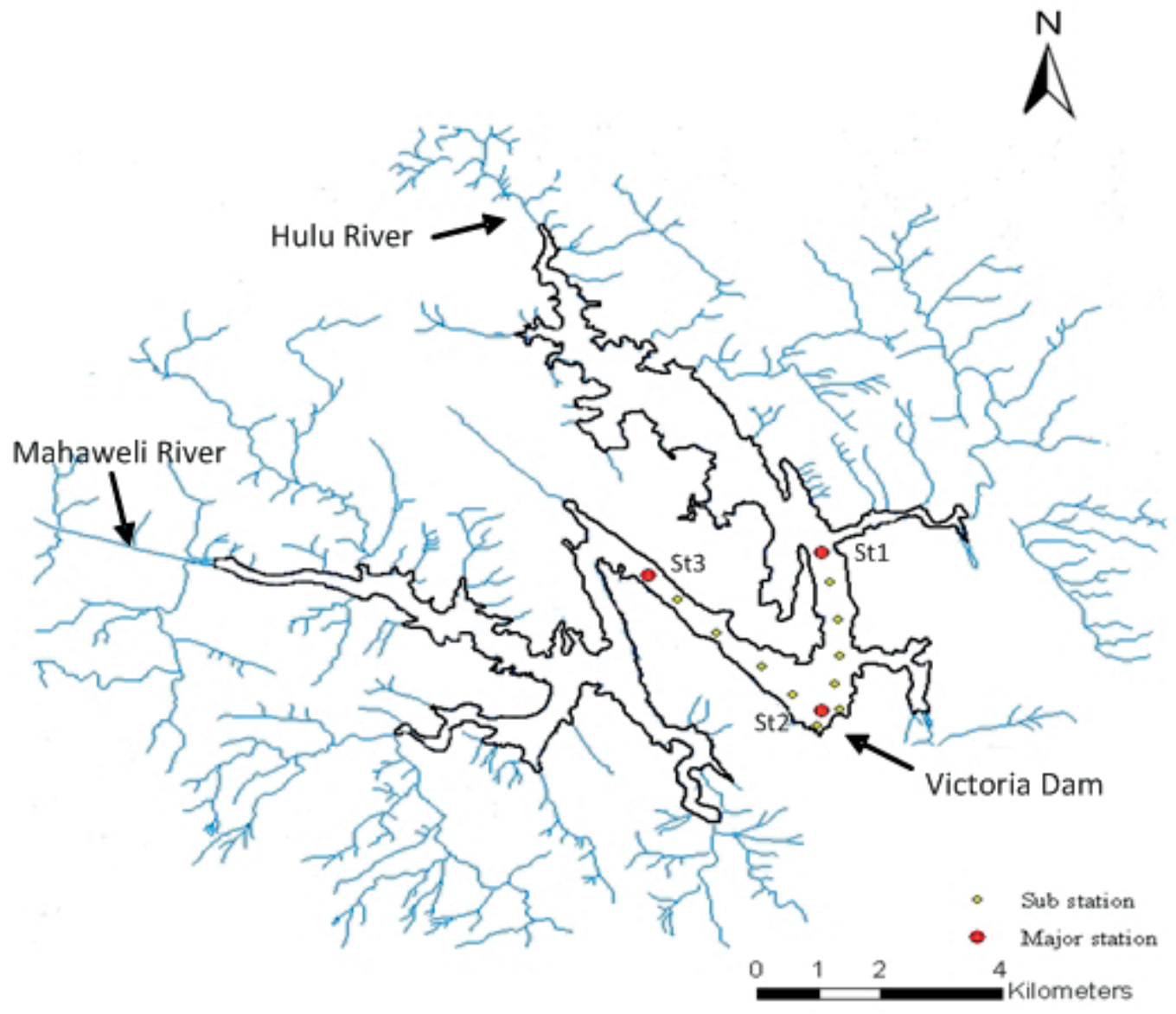

Figure 1 - Sampling stations and major inflowing rivers of the Victoria reservoir 
Table 1 - General and morphometric characteristics and Physico-chemical data of the Victoria reservoir

\begin{tabular}{ll}
\hline (a) General Characteristics & \\
\hline Latitude & $7^{\circ} 15^{\prime} \mathrm{N}$ to $7^{\circ} 19^{\prime} \mathrm{N}$ \\
Longitude & $80^{\circ} 39^{\prime} \mathrm{E}$ to $80^{\circ} 48^{\prime} \mathrm{E}$ \\
Full supply level & $438.0 \mathrm{~m} \mathrm{MSL}$ \\
Extreme flood level & $441.2 \mathrm{~m} \mathrm{MSL}$ \\
Minimum operating level & $370.0 \mathrm{~m} \mathrm{MSL}$ \\
Storage capacity & $721.2 \times 10^{6} \mathrm{~m}^{3}$ \\
(at Full supply level) & $34.0 \times 10^{6} \mathrm{~m}^{3}$ \\
(at Minimum operating level) & $1891 \mathrm{~km}^{2}$ \\
Catchment area & Mahaweli River, Hulu River \\
Major inflowing rivers & Galmal Oya, Mool Oya, Thalathu Oya, \\
Minor inflowing rivers & Kiwiliyadda Oya, Kapuliyadda Oya, \\
& Mahaweli river \\
Outflowing river & \\
\hline (b) Morphometric Characteristics & $21.14 \mathrm{~km}^{2}$ \\
\hline Surface area & $6.8 \mathrm{~km}$ \\
Maximum length & $2.41 \mathrm{~km}$ \\
Maximum breadth & $98 \mathrm{~m}$ \\
Maximum depth & $30.5 \mathrm{~m}$ \\
Mean depth & $165 \mathrm{~km}$ \\
Shore line (SL) & $105 \mathrm{~m}{ }^{3} / \mathrm{sec}$ \\
Mean river flow & \\
\hline (c) Physio-chemical data & $24.8-31.2^{\circ} \mathrm{C}$ \\
\hline Surface temperature & $24.2^{\circ} \mathrm{C}$ \\
Hypolimnion temperature & $53.3-105.2 \mu \mathrm{S} \mathrm{cm}^{-1}$ \\
Conductivity (surface) & $6.03-8.65$ \\
pH (surface) & $0.65-3.25 \mathrm{~m}$ \\
Transparency (Secchi disk) & \\
Temperature (inflowing rivers) & $22.4-27.2^{\circ} \mathrm{C}$ \\
\hline
\end{tabular}

Table 2 - Average monthly climatological elements of the Victoria reservoir for the period 1992-1999

\begin{tabular}{|c|c|c|c|c|c|c|c|c|c|c|c|c|}
\hline & Jan & Feb Mar & Apr & May & Jun & Jul & Aug & Sep & Oct & Nov & Dec & Total \\
\hline Rainfall (mm) & 194 & $95 \quad 46$ & 93 & 65 & 40 & 36 & 72 & 76 & 188 & 193 & 162 & 1259 \\
\hline \multicolumn{13}{|l|}{ Temperature } \\
\hline Average $\left({ }^{\circ} \mathrm{C}\right)$ & 23.6 & 24.826 .0 & 27.4 & 28.0 & 26.8 & 27.0 & 26.2 & 26.8 & 25.8 & 25.0 & 23.6 & \\
\hline Maximum $\left({ }^{\circ} \mathrm{C}\right)$ & 27.6 & 29.231 .8 & 32.6 & 33.0 & 31.4 & 31.2 & 31.2 & 30.8 & 30.0 & 29.4 & 28.0 & \\
\hline Minimum $\left({ }^{\circ} \mathrm{C}\right)$ & 19.8 & 20.220 .2 & 22.0 & 22.8 & 22.6 & 22.8 & 22.0 & 22.8 & 21.4 & 20.8 & 19.6 & \\
\hline Wind speed $(\mathrm{km} / \mathrm{h})$ & 2.8 & $2.0 \quad 1.7$ & 2.4 & 3.6 & 5.6 & 5.8 & 5.2 & 3.2 & 2.7 & 2.1 & 2.0 & \\
\hline Evaporation (mm) & 78 & 76121 & 88 & 114 & 104 & 106 & 96 & 104 & 71 & 62 & 57 & 1077 \\
\hline Sunshine hours & 6.8 & $6.8 \quad 8.9$ & 6.6 & 7.8 & 4.8 & 4.8 & 5.5 & 6.5 & 5.7 & 6.1 & 6.1 & \\
\hline
\end{tabular}

The table describes that the lowest temperatures occur from January to February and November to December and the highest temperatures occur from April to September. Rainfall varies considerably during the year. Highest rainfall occurs in January and from 
October to December. Wind speed varies considerably (measured at $2 \mathrm{~m}$ above ground surface) during the year. The mean monthly wind speed is highest in June to August and lowest in the period from January to April and from October to December. The average annual evaporation around the Victoria reservoir is $1077 \mathrm{~mm}$. Monthly variation of evaporation follows the mean temperature and total radiation variations.

Limnological investigations have been conducted (Piyasiri 1991) since 1987 to understand the trophic nature of the reservoir. Piyasiri (1991) concluded that the Victoria reservoir is a tropical oligomictic water body. The Victoria reservoir faced several water quality related problems in the past. It reached a pre blooming stage in March 2003 indicating high densities of Microcystis aeruginosa when reservoir was filled up to two third of its full capacity. This indicates its high sensitivity towards eutrophication and blooming.

\section{Methodology}

\subsection{Hydrodynamic Model: DYRESM}

The assumption of one-dimensionality in DYRESM is based on the density stratification usually found in lakes and reservoirs, which inhibits vertical motions while lateral and longitudinal variation in density are quickly relaxed by horizontal convection, occurring on time scales shorter than vertical advection. The model has been developed with emphasis on parameterization of the physical processes rather than numerical solution of the appropriate differential equations.

DYRESM uses a Lagrangian layer scheme in which the reservoir is represented by a series of horizontal layers of uniform property but of variable thickness. As inflows and outflows enter or leave the reservoir, the affected layers expand or contract and those above move up or down to accommodate the volume change. The vertical movement of layers is accompanied by a thickness change as the layer surface areas change with vertical position in accordance with the reservoir bathymetry. Mixing is modeled by amalgamation of adjacent layers, and the layer thicknesses are dynamically set internally by the model to ensure that for each process, an adequate resolution is obtained.
Even with the assumption of onedimensionality, the vertical density structure is the result of a complex interaction of a number of processes active in lakes and reservoirs. These individual processes are parameterized in DYRESM. The development of DYRESM is described in detail in the literature (Imberger et al. 1978; Imberger and Patterson 1981, Patterson et al. 1984), including descriptions of the process parameterizations. The processes included in the model are surface heat, mass and momentum exchanges, surface mixed layer deepening model, inflow, outflow, mixing in the hypolimnion and bubble plume destratification.

The model is constructed as a main programme with subroutines, which separately model each of physical processes of inflow, withdrawal, mixed layer dynamics and vertical transport in the hypolimnion. In addition there are a number of service subroutines, which provide maintenance of the layer system (volume, position, etc.) and provide calculations of physical properties, which are frequently required such as density. The functions of the main programme are therefore of input/output, the calculation of fixed parameters and control over timing of the calls to the various process subroutines.

The data required for the DYRESM model are daily values of air temperature, relative humidity, wind velocity, solar radiation, rainfall, evaporation, inflow quantity, inflow quality and outflow quantity.

The model DYRESM has been used widely to study behaviour of reservoirs (Imberger 1981, Spigel and Ogilvie 1985, Campos et al. 2001, Antenucci et al. 2002, Gal et al. 2003, Nandalal et al. 2005).

\subsection{Statistical Analysis (Fit statistics)}

The ability of the model to simulate observed conditions was tested with two goodness-of-fit statistics: the root mean squared error (RMSE), and the mean of the relative absolute error (MRAE).

The RMSE is defined as the square root of the mean of the squared difference between observed and simulated values.

$$
R M S E=\sqrt{\frac{1}{n} \sum_{i=1}^{n}\left(x_{s, i}-x_{o, i}\right)^{2}}
$$


Where, $x_{s, i}$ and $x_{0, i}$ are the simulated and observed $i^{\text {th }}$ values and, $n$ is the sample size. In this analysis, the root mean square error was used as the measure of error between computed and observed temperatures.

As such, the RMSE is similar to a standard deviation of the error (Rounds and Wood, 2001), roughly two-thirds of the errors are expected to fall within \pm 1 . RMSE values have the units of the quantity of interest, and lower values indicate a better fit. For the statistic to be relevant, however, one must know the range of the fitted data to determine whether an RMSE indicates an excellent or poor fit.

The MRAE is the mean of the absolute value of relative errors. Lam et al. (1983) expressed this statistic as the following,

$M R A E=\frac{1}{n} \sum_{i=1}^{n} \frac{\left|x_{o, i}-x_{s, i}\right|}{x_{o, i}}$

Variables are as defined before.

There are limitations for using the above equation, specifically, there is poor behaviour of MRAE at low values of $x_{o . i}$ and the variability of the data is not adequately recognized. The MRAE is also constrained if $x_{o . i}$ is much greater than $x_{s, i}$. However, an advantage of the MRAE is that this statistic is a readily understood comparison and can provide a gross measure of model adequacy and can be useful in comparing models.

\subsection{Data collection}

The study area of the reservoir and its tributaries are depicted in Figure 1. Water samples have been collected once a month from three stations St.1, St.2, and St.3, vertically from top to bottom at $10 \mathrm{~m}$ intervals. Physical, chemical and biological water quality parameters measured in these water samples are temperature, dissolved oxygen concentration, electrical conductivity, $\mathrm{pH}$, chloride, total alkalinity, suspended solids, nitrogen, ammonia, nitrate, nitrite, biological oxygen demand, fluoride, heavy metals, chlorophyll and phytoplankton. This study uses the data collected at the station St.2. These water quality data have been collected through limnology project at Mahaweli reservoirs by the Department of Zoology, University of Sri Jayawardenapura, Sri Lanka (Piyasiri, 1996).
The daily values of air temperature, relative humidity, wind velocity, rainfall, evaporation, reservoir inflow quantity, inflow quality and outflow quantity, which are required for the model were collected from Headworks Administration, Operation and Maintenance unit of the Mahaweli Authority of Sri Lanka. Actual duration of sun shine hours, which were used to estimate solar radiation, were collected from Natural Resource Management Centre at Peradeniya, Sri Lanka.

\section{Analysis}

\subsection{Data for the model}

The DYRESM model for the Victoria reservoir was calibrated using the data collected during 1995. Except short wave radiation and daily inflow temperatures, all the other data required for the model were available for that year. However, records of daily sunshine duration were available for the area. Using that, the short wave radiation were estimated based on the Angstrom formula (Allen et al. 1998), which relates solar radiation to extraterrestrial radiation and relative sunshine duration.

Maximum possible duration of sunshine hours and extraterrestrial radiation for different latitudes listed in FAO publication No.56 were adopted in the study (Allen et al, 1998). The constants in the Angstrom formula were obtained from the modified Fre're curves for Sri Lanka by Samuel (2000). Daily inflow temperatures were estimated as the average of the air temperatures during the 4 days preceding the date of the inflow entering the reservoir, as suggested by the model developers.

Initial reservoir water level, temperature and salinity are required to start a simulation. Initial water level was set to the observed water level of the reservoir on the first day of simulation period. Observed water temperature and salinity profiles at St.2 on that day were available for the initial condition of the reservoir.

\subsection{Model parameters}

The model parameters are given in Table 3 . However, many of them cannot be measured directly and were obtained by a trial and error procedure of comparing the temperature 
obtained from the model DYRESM simulations with observations. Most of the hydrodynamic and thermal processes in a reservoir are simulated in the DYRESM model. The mean albedo of water, emissivity of water surface and light extinction coefficient were found to be very sensitive parameters, while the other parameters were relatively insensitive.

A large number of simulations with DYRESM were carried out by changing model parameters until the simulated temperatures were very close to the observed data, for the period $9^{\text {th }}$ January to 31 ${ }^{\text {st }}$ December 1995 for the
Victoria reservoir. The adopted model calibration process is described below.

\subsection{Reservoir mass balance}

The model gives reservoir water level during the simulation period. It was compared with the observed reservoir water levels during the simulation period from $9^{\text {th }}$ January to $31^{\text {st }}$ December 1995, and they were found to be in good agreement as shown in Figure 2. RMSE between measured and simulated water levels was $0.03 \mathrm{~m}$. The difference between measured and simulated water levels ranged from -0.17 to $0.32 \mathrm{~m}$, and the mean difference was $0.06 \mathrm{~m}$.

Table 3 - Parameters of the DYRESM model for the Victoria reservoir

\begin{tabular}{ll}
\hline Parameter & Value \\
\hline Neutral 10 m aerodynamic drag coefficient & $1.3 \times 10^{-3}$ \\
Mean albedo of water & 0.5 \\
Emissivity of a water surface & 0.99 \\
Light extinction coefficient & 0.4 \\
Critical wind speed at $10 \mathrm{~m}$ height $\quad\left[\mathrm{m} \mathrm{s}^{-1}\right]$ & 4.00 \\
Time of day for output (in seconds from midnight) & 43200 \\
Entrainment coefficient constant & $2.0 \times 10^{-3}$ \\
Bubbler entrainment coefficient & 0.006 \\
Buoyant plume entrainment coefficient & 0.083 \\
Shear production efficiency & 0.06 \\
Potential energy mixing efficiency & 0.20 \\
Wind stirring efficiency & 0.06 \\
Effective surface area coefficient & $1.0 \mathrm{E}+07$ \\
Vertical mixing coefficient & 200 \\
\hline
\end{tabular}

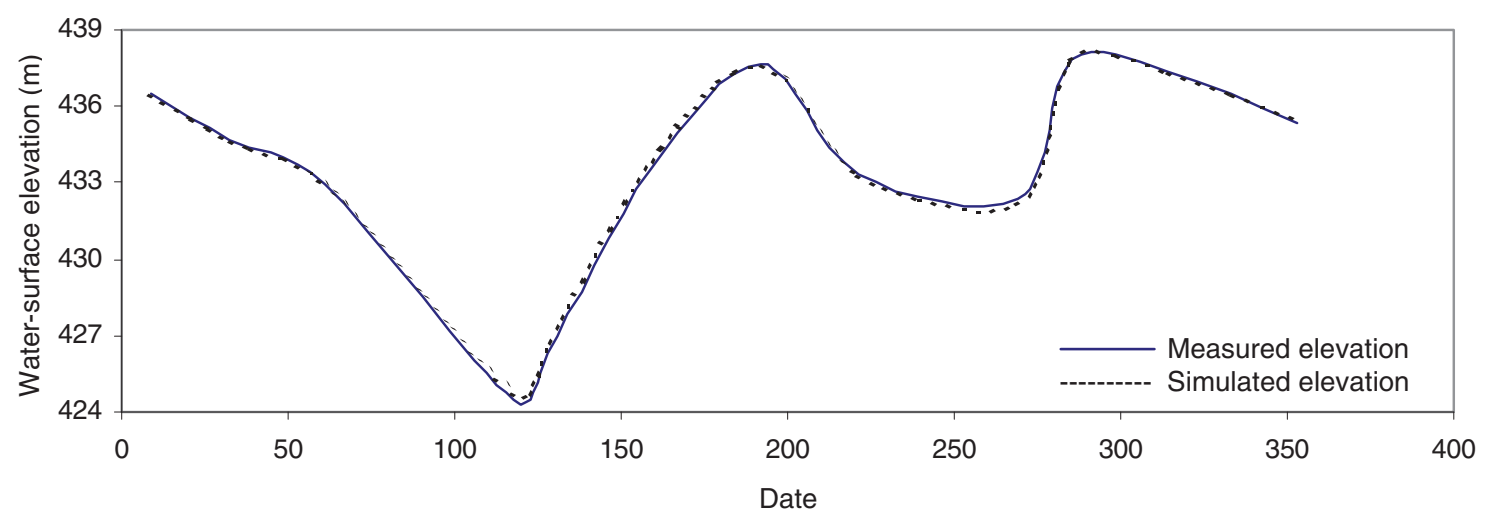

Figure 2 - Observed and simulated reservoir level in the Victoria reservoir at St 2 during calibration

\subsection{Temperature variation}

The effects of inflow water temperature, surface heat exchange (which includes the effects of solar radiation and wind), bottom heat exchange, transport of heat, and internal mixing (including the effects of the withdrawal at the
Victoria dam) are included in the simulation of water temperature.

The DYRESM simulated water temperatures (118 observations) from January through December 1995 were compared with corresponding observed values for St 2 during 
the calibration stage to decide the model parameter values. In Figure 3 the simulated and measured vertical reservoir water temperature profiles at different days of the year are presented. The model simulates the onset of stratification, mixed layer depth and water temperatures quite accurately. Measured water temperatures ranged from $24.4{ }^{\circ} \mathrm{C}$ to $29.3{ }^{\circ} \mathrm{C}$. Differences between measured and simulated temperatures ranged from $-0.9{ }^{\circ} \mathrm{C}$ to $1.2{ }^{\circ} \mathrm{C}$ with a RMSE of 0.24. The MARE between measured and simulated water temperatures was $1.55 \%$. Eighty nine percent of the simulated temperatures were within $1^{\circ} \mathrm{C}$ of the measured temperature.

The error statistics for the simulated vertical profiles of water temperature were calculated for the calibration period. The monthly goodness of-fit statistics between observed and simulated temperatures are given in Table 4.

Table 4 - Goodness-of-fit statistics between observed and simulated temperatures during the calibration period for the Victoria reservoir

\begin{tabular}{|c|c|c|c|c|c|c|c|c|c|c|c|c|c|}
\hline & \multicolumn{13}{|c|}{ Calibration year 1995} \\
\hline & Jan 9 & Feb 1 & Mar 2 & Apr 28 & May 8 & Jun 8 & Jul 11 & Aug 9 & Sep 26 & Oct 12 & Nov 10 & Dec 19 & Mean \\
\hline $\operatorname{RMSE}\left( \pm{ }^{\circ} \mathrm{C}\right)$ & 0.001 & 0.145 & 0.057 & 0.318 & 0.422 & 0.313 & 0.228 & 0.243 & 0.251 & 0.364 & 0.428 & 0.158 & 0.244 \\
\hline MRAE (\%) & 0.026 & 1.367 & 0.807 & 1.964 & 2.157 & 1.800 & 1.647 & 1.525 & 1.553 & 2.119 & 2.308 & 1.367 & 1.553 \\
\hline
\end{tabular}

\subsection{Verification of the DYRESM}

To verify the accuracy of the parameters of the model calibrated based on the data in the year 1995, the Victoria reservoir was simulated for the period January $17^{\text {th }}$ through December $31^{\text {st }}$, 1996.

Simulated water temperatures in 1996, using the same parameter values obtained from the 1995 calibration, were very similar to measured temperatures.

Figure 4 presents the comparison of all observed water temperatures (86 observations) for January through December 1996 with corresponding simulated values for St 2 . Observed water temperatures in 1996 ranged from 23.6 to $28.7^{\circ} \mathrm{C}$. Differences between observed and simulated temperatures ranged from -1.58 to $1.08^{\circ} \mathrm{C}$ with a RMSE of 0.24 . The MRAE between measured and simulated water temperature was $1.55 \%$, indicating a good calibration of the model. Ninety one percent of the simulated temperatures were within $1^{\circ} \mathrm{C}$ of the measured temperature. Simulated water temperatures during the 1996 verification period, like the 1995 calibration period, provided an excellent simulation of water temperature in the Victoria reservoir with most simulated values within plus or minus $1^{\circ} \mathrm{C}$ of the observed value.

The fit statistics were calculated for the verification period, too. The monthly goodness of-fit statistics between observed and simulated temperatures are given in Table 5.

\subsection{Application of the model}

The calibrated hydrodynamic model (DYRESM) was used to run different operational scenarios which are useful to make decisions for improving water quality in the Victoria reservoir. Simulations were developed to evaluate the stratification cycle during a period of 3 years. Impact of withdrawal quantity and withdrawal level on stratification in the reservoir was investigated based on the model.

\subsection{Simulation for a 3 years period}

After verification, the calibrated DYRESM model was run for a period of three years from 1997 to 1999 to study the stratification in the Victoria reservoir. Initially, historical releases were used in the simulation. Figure 5 (a) shows the resulted distribution of water temperature in the reservoir during that period.

The results show that the water temperature varied annually, seasonally and spatially in the Victoria reservoir. Thermal stratification is strong during the warm period approximately from March to August. During the warm period in 1997 and 1999 water temperatures range from around $29^{\circ} \mathrm{C}$ at the surface to nearly $25^{\circ} \mathrm{C}$ at the deeper levels. Surface water temperature is about $31^{\circ} \mathrm{C}$ for the period MayJune in 1998. During the cold period (approximately from October to February) the reservoir water gets mixed and top to bottom temperature vary from $26^{\circ} \mathrm{C}$ to $25^{\circ} \mathrm{C}$ only. 

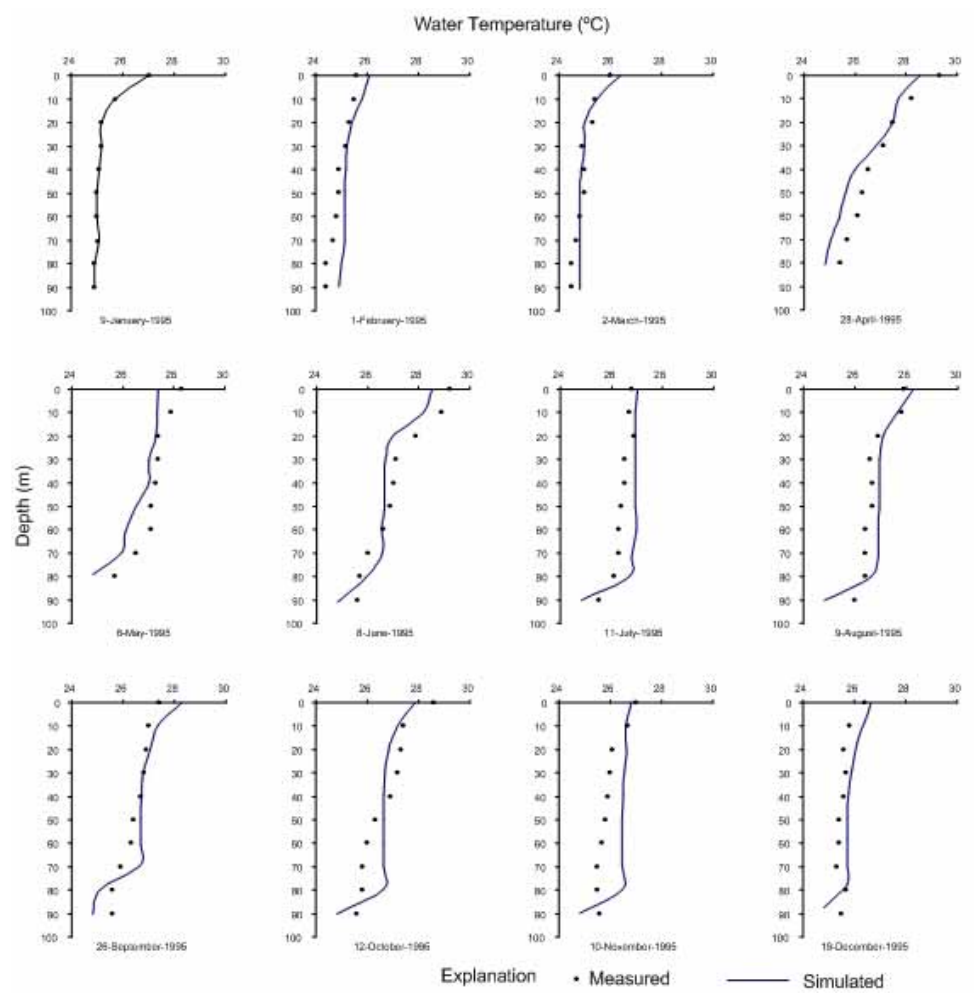

Figure 3 - Measured and simulated vertical profiles of water temperature at Victoria reservoir St 2, during 1995

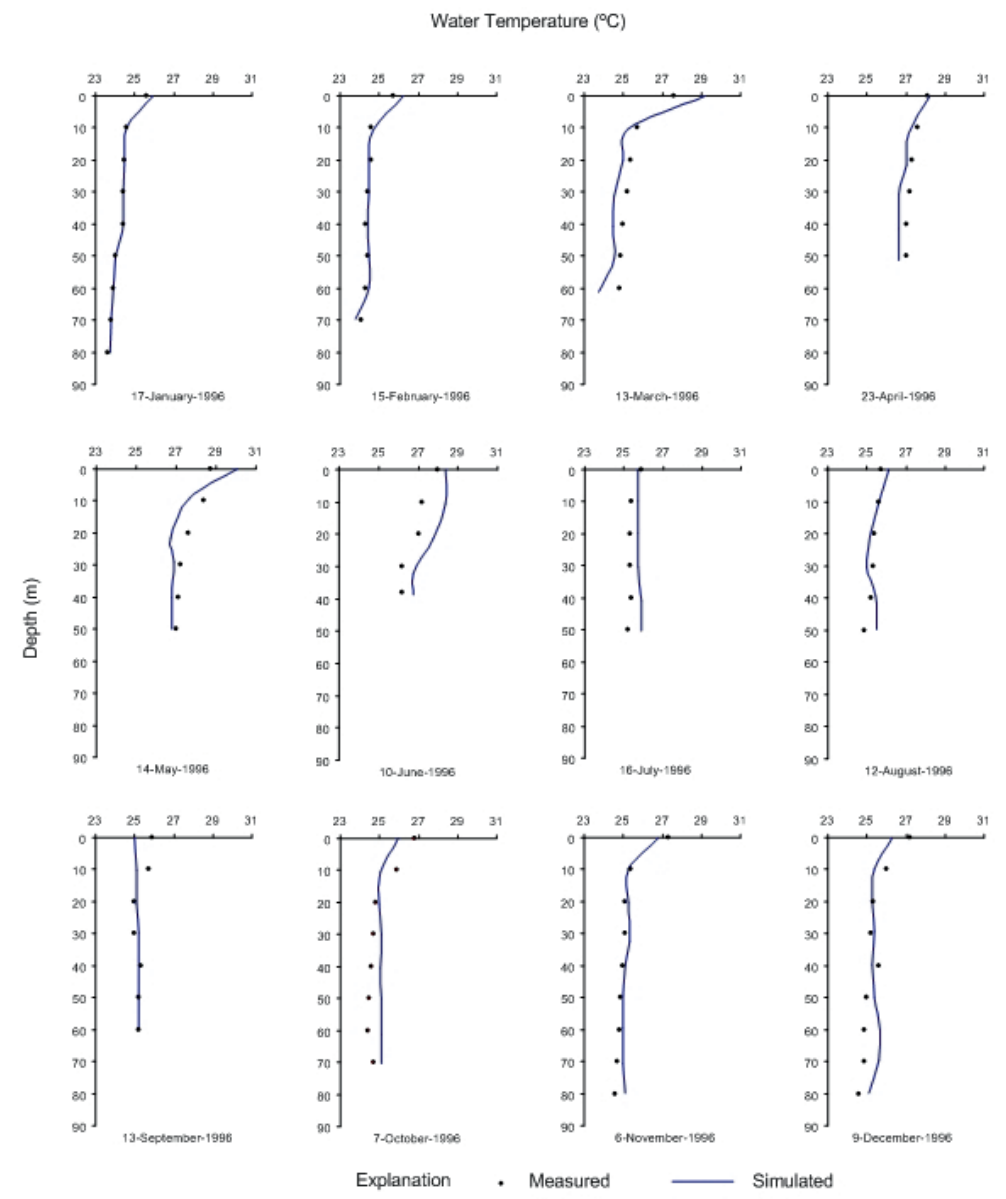

Figure 4 - Measured and simulated vertical profiles of water temperature at Victoria reservoir St 2, during 1996 
Table 5 - Goodness-of-fit statistics between observed and simulated temperatures during the verification period for the Victoria reservoir

\begin{tabular}{|c|c|c|c|c|c|c|c|c|c|c|c|c|c|}
\hline & \multicolumn{13}{|c|}{ Verification year 1996} \\
\hline & Jan 17 & Feb 15 & Mar 13 & 3 Apr 23 & 3 May 1 & 14Jun 10 & Jul 16 & Aug 1 & 2Sep 13 & Oct 7 & Nov 6 & $\operatorname{Dec} 9$ & Mean \\
\hline $\operatorname{RMSE}\left( \pm{ }^{\circ} \mathrm{C}\right)$ & 0.013 & 0.060 & 0.700 & 0.151 & 0.554 & 0.541 & 0.211 & 0.129 & 0.181 & 0.347 & 0.077 & 0.305 & 0.272 \\
\hline MRAE (\%) & 0.198 & 0.762 & 2.816 & 1.330 & 2.260 & 2.537 & 1.693 & 1.241 & 1.087 & 2.169 & 0.944 & 1.877 & 1.576 \\
\hline
\end{tabular}

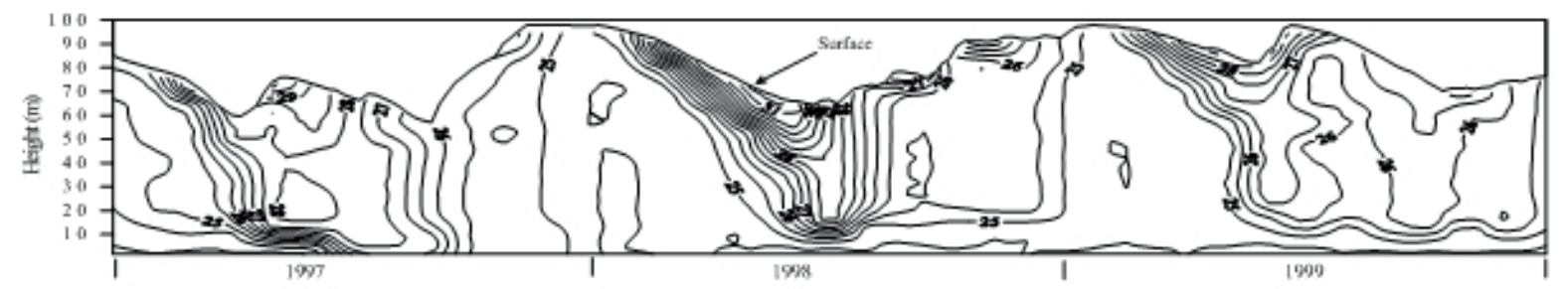

(a)

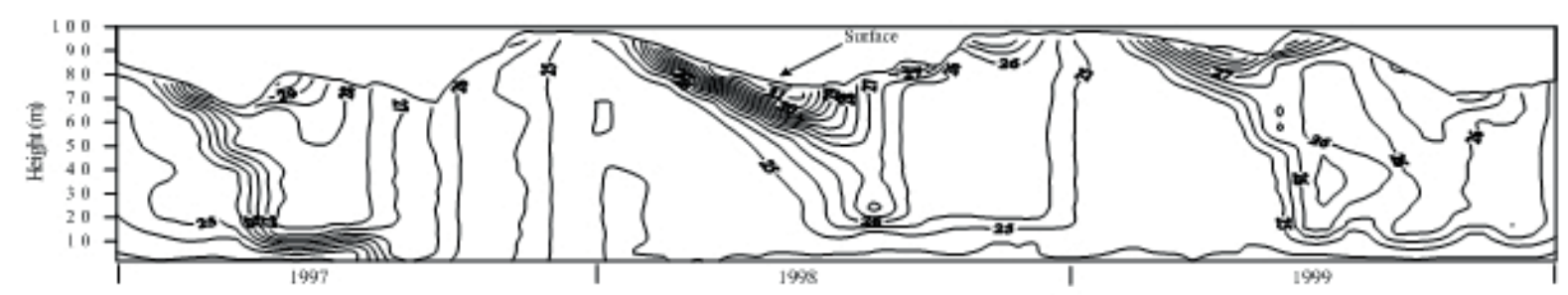

(b)

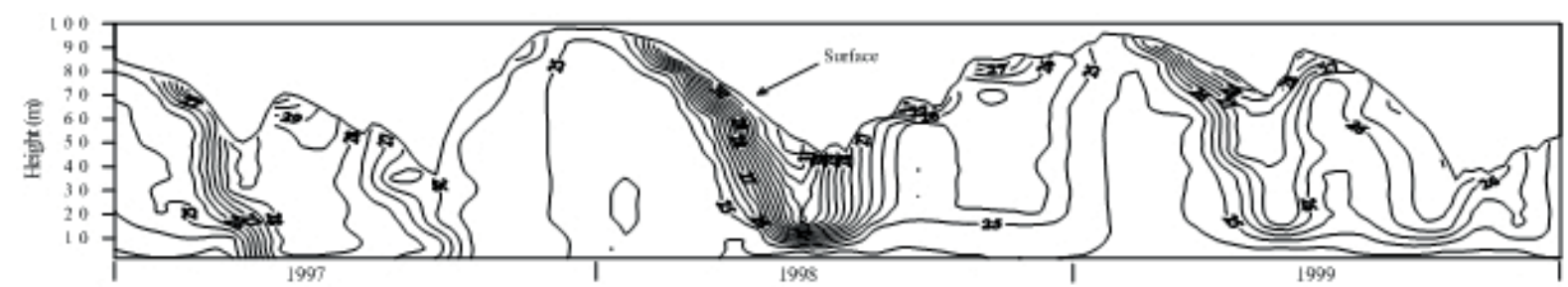

(c)

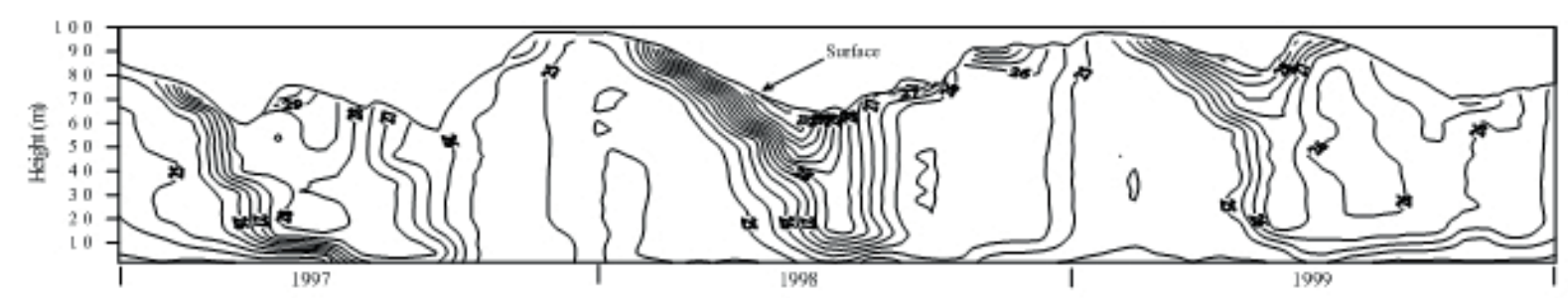

(d)

Figure 5 - Distribution of water temperature in the Victoria reservoir St 2, from January 1997 to December 1999: (a) Historical operation, (b) Release quantity reduced, (c) Release quantity increased, and (d) Release from outlets at different levels.

\subsection{Impact of the withdrawal quantity}

Reservoir release quantity has an impact on thermal stratification. Reservoir behaviour was studied with a different reservoir release pattern using two simulations. In the first, the release from the upper outlet was decreased by
$25 \%$ and in the second, the release was increased by $25 \%$ for the period from March to May (at the onset of stratification period) in all the three years. Note that the dam has two outlets at different levels. The release during the other period was kept unchanged. Figures 5 
(b) and (c) show the resulted distributions of water temperature.

The results clearly indicate that the thermal stratification is affected by the change in the release quantity. When release quantity was decreased by $25 \%$ reservoir stratification has slightly decreased. However, the stratification has slightly increased when the release quantity was increased by $25 \%$. This suggests the possibility to change the strong stratification in the Victoria reservoir by manipulating the releases.

\subsection{Simulation of impact of the withdrawal level}

Impact of the outlet elevation on the thermal stratification and thus on water quality was studied next. For that, $75 \%$ of water was withdrawn from the upper outlet $(15 \mathrm{~m}$ above the bottom) and $25 \%$ from lower one $(8.2 \mathrm{~m}$ above the bottom) during the onset of stratification period, March to May, in all the three years. Total release was made through the upper outlet during the balance period. Figure $5(d)$ shows the resulted distributions of water temperature. The results indicate that the outlet elevation affects the thermal stratification in the reservoir. The thermocline has become deeper when water is released through both outlets. The surface temperature has not changed, but the bottom water temperature has improved considerably. Besides, stratification is observed to be reduced significantly. Releasing from the bottom outlet (at the onset of the warm period), where water is found to be stratified is observed to be a good operation pattern to improve water quality in the reservoir. This suggests the possibility to decrease strong stratification in the Victoria reservoir by manipulating releases.

\section{Conclusions}

A one-dimensional hydrodynamic model, DYRESM, was calibrated and verified for the simulation of thermal stratification of the Victoria reservoir in Sri Lanka. The model predicted thermal stratification in the reservoir with fair precision. Predictions of the onset of stratification, surface temperature, hypolimnetic temperature and mixed-layer depths were all in agreement with the observations. The quantitative and qualitative criteria of model prediction showed that the model could simulate the annual dynamics reasonably well. The Victoria reservoir was observed to be thermally stratified during the warm periods of the year.

The model enables the prediction of thermal stratification in the reservoir body using data that can be collected easily, such as climatological data and reservoir inflow quantity and quality. This could avoid continuous expensive reservoir water quality monitoring programmes.

The three year long (1997-1999) simulation showed that the annual cycle of stratification clearly. Since thermal stratification in a reservoir determines the water quality in a reservoir body, the model enables predicting adverse effects with respect to water quality in the reservoir. In such situations, reservoir managers will be able to take precautionary measures by controlling stratification in the reservoir by manipulating withdrawals. The study, based on two different withdrawal patterns, has shown that stratification in the Victoria reservoir could be altered by manipulating the withdrawal. Thus, the impact of many alternative operational patterns on thermal stratification in the reservoir could be studied with the help of the model in advance to avoid adverse water quality conditions in the reservoir as well as supplied from the reservoir.

Results from this study will provide reservoir management with information to better understand how changes in hydrology and water quality in the basin affects water quality in the reservoir. With this information, managers will be able to more effectively manage their reservoir.

\section{Acknowledgements}

National Science Foundation, Sri Lanka for providing financial assistance through its research grant RG 2001/E01, Headworks Administration, Operation and Maintenance unit of the Mahaweli Authority of Sri Lanka and Natural Resource Management Centre at Peradeniya, Sri Lanka for providing data and Centre for Water Research, University of Western Australia for giving permission to use the DYRESM model are greatly acknowledged.

\section{References}


1. Abeysinghe, K.G.A.M.C.S., Nandalal, K.D.W. and S. Piyasiri (2005) "Prediction of thermal stratification of the Kotmale reservoir using a hydrodynamic model", Journal of the National Science Foundation of Sri Lanka, Vol.33, No.1, pp.25-36.

2. Allen, R.G., Pereira, L.S., Raes, D. and M. Smith (1998) "Crop evapotranspiration Guidelines for computing crop water requirements", FAO Irrigation and drainage paper $56, \mathrm{FAO}$, Rome.

3. Antenucci, J.P., Alexander, R. Romero, J.R. and J. Imberger (2002) "Management strategies for a eutrophic water supply reservoir - San Roque, Argentina", Proceedings of IWA $3^{\text {rd }}$ World Congress, Australia.

4. Campos, H., Hamilton, D.P., Villalobos, L. Imberger, J. and A. Javan (2001) "A modelling assessment of potential for eutrophication of lake Rinihue, Chilie", Arch. Hydrobiology, pp.101-125.

5. Dake, J.M.K. and D.F.R. Harleman (1969) "Thermal stratification in lakes-analytical and laboratory Studies", Water Resources Research, 5, 484-495.

6. Gal, G., Parparvo, A., Wagner, U. and T. Rozenberg (2003) "Testing the impact of management scenarios on water quality using ecosystem model", Annual report to Israel Water Commission, pp.215.

7. Hamilton, D. P. and S.G. Schladow (1997) "Prediction of water quality in lakes and reservoirs. Part I. Model description", Ecological Modeling, 96, 91-110.

8. Hostetler, S.W. and P.J. Bartlein (1990) "Simulation of lake evaporation with application to lake level variations of Harney-Malheur, Oregon", Water Resources Research, Vol.26, No. pp.26032612.

9. Huber, W. C., Harleman, D. R. F. and P.J. Ryan (1972) "Temperature prediction in stratified reservoirs", Journal of Hydraulics Division, ASCE, 98, 645-665.

10. Imberger, J. (1981) "The influence of stream salinity on reservoir water quality", Agricultural water management, Vol.4, pp.255-273.
11. Imberger, J., Patterson, J. C., Hebbert, B. and I.C. Loh (1978) "Dynamics of Reservoir of Medium Size", Journal of the Hydraulic Division, ASCE, 104(HY5), 725743.

12. Imberger, J. and J.C. Patterson (1981) "A dynamic reservoir simulation modelDYRESM", 5, in H.B. Fisher (ed), Transport Models for Inland and Coastal Waters, Academic Press Inc., New York, USA, pp.310-361.

13. Joehnk, K.D. and L. Umlauf (2001) "Modeling the metalimnetic oxygen minimum in a medium sized alpine lake", Ecological Modeling, Vol.136, pp.6780 .

14. Lam, D.L.C., Schertzer, W.M. and A.S. Fraser (1983) "Simulation of Lake Eire Water Quality Responses to Loading and Weather Variations", IWD Scientific Series No.134, National Water Research Institute, Canada Centre for Inland Waters, Burlington, 232p

15. Markofsky, M. and D.R.F. Harleman, D.R.F. (1973) "Prediction of Water Quality in Stratified Reservoirs", Journal of the Hydraulic Division, ASCE, 99(HY5), 729-745.

16. Nandalal, K.D.W. (1995) "Reservoir Management Under Consideration of Stratification and Hydraulic Phenomena", PhD Dissertation, Department of Water Resources, Wageningen Agricultural University, The Netherlands.

17. Nandalal, K.D.W., Abeysinghe, K.G.A.M.C.S. and S. Piyasiri (2005) "Improvement of Water Quality in a Reservoir: Case of Kotmale Reservoir in Sri Lanka", Abstracts Volume, 11 $1^{\text {th }}$ World Lakes Conference, Nairobi, Kenya, p.26.

18. O' Connor and D.J. Mueller (1970) "A Water Quality Model of Chloride in Great Lakes", Journal of the Sanitary Engineering Division, ASCE, Vol.96, No.SA4, August, pp.955-975.

19. Orlob, G. T. (1983) "Mathematical modeling of water quality: streams, lakes and reservoirs", In: Orlob, G. T. (Ed.). 
Series on Applied System Analysis. Wiley IIASA, Inter.

20. Patterson, J. C., Hambling, P. F. and J. Imberger (1984) Classification and dynamic simulation of the vertical density structure of lakes, Limnological Oceanography, 29, 845-861.

21. Piyasiri, S. (1991) "Limnology project at Mahaweli Reservoirs, Some properties of Kotmale, Victoria and Randenigala reservoirs", Vidyodaya Journal of Science, Vol. 3 No. 1, pp. 45-61.

22. Piyasiri, S. (1996) "The Chlorophyll-a content, species composition and population structure of phytoplankton in Randenigala reservoir in Sri Lanka",
Vidyodaya Journal of Science, Vol. 5. No.1, pp. 29-41.

23. Rounds, S.A. and T.M. Wood (2001) "Modeling water quality in the Tualatin River, Oregon, 1991-1997", WaterResources Investigations Report 01-4041.

24. Samuel, T.D.M.A. (2000) "Solar radiation distribution over Sri Lanka", Bulletin No.1, Solar Research Laboratory, University of Peradeniya, Sri Lanka.

25. Spigel, R.H. and D.J. Ogilvie (1985), "Importance of selective withdrawal in reservoirs with short resident times: A case study", Proceedings of the $21^{\text {st }}$ IAHR Congress, Melbourne, Australia, pp.275279. 